\title{
Design and characterization of camptothecin gel for treatment of epidermoid carcinoma
}

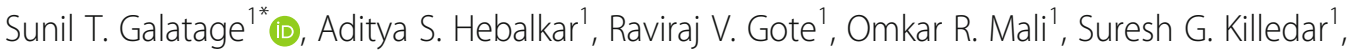 \\ Durgacharan A. Bhagwat ${ }^{2}$ and Vijay M. Kumbhar ${ }^{3}$
}

\begin{abstract}
Background: The objective of present research work is to design and characterize camptothecin gel using Carbopol934 for the treatment of epidermoid carcinoma. Optimized herbal gel formulations were evaluated for homogeneity and appearance, viscosity, extrudability, spreadability, drug content, drug release, $\mathrm{pH}$, and in vitro skin cancer activity on A431 cell lines.

Results: Mass and Infrared Spectra respectively conforms molecular weight and functional groups present in camptothecin. All the formulations F1 to F5 showed good homogeneity, pH from 6.68 to 6.90 , spreadability in the range of $15.81-23.37 \mathrm{gm} . \mathrm{cm} / \mathrm{s}$, extrudability $85.51-90.45 \% \mathrm{w} / \mathrm{W}$, drug content $89.12-96.64 \%$, and in vitro diffusion 88.36-98.40\%, respectively. The drug release study showed that all the formulations followed a diffusion-controlled, zero-order release mechanism. Anticancer activity results indicate that camptothecin gel induce cell death in A-439 cells having $\mathrm{IC}_{50} 48.03 \mu \mathrm{g}$ and \% apoptosis $54.67 \pm 4.58$.

Conclusion: Topical delivery of camptothecin alleviates the side effects caused by systemic chemotherapy; hence, the developed herbal gel formulation can be effectively useful to deliver camptothecin in the treatment of epidermoid carcinoma on A-431 cells.
\end{abstract}

Keywords: Skin cancer, Camptothecin, Diffusion, Herbal gel, Drug content, Cell line-A431

\section{Background}

Nowaday's burden of growing global cancer was drastically raised, and patients suffering from it deeply required an ideal therapy that completely cures the cancer [1]. Current treatments of cancer include chemotherapy, surgery, and radiation therapy, having hazardous adverse effects. From the ancient era, various types of cancer were cured and prevented by using natural and herbal drugs [2]. Epidermoid carcinoma, also known as skin cancer, is a more versatile and common cancer in human being. Ultraviolet radiations which are present in sunlight are prominent source of skin cancer. Change in appearance of

\footnotetext{
*Correspondence: gsunil201288@gmail.com

'Sant Gajanan Maharaj College of Pharmacy, Mahagaon, Site: Chinchewadi, Kolhapur, Maharashtra 416502, India

Full list of author information is available at the end of the article
}

the skin and a sore that does not heal within 2 weeks are primary indicators and signs of skin cancer. It has been estimated that 2-3 million new cases occur annually and the number is increasing each year. It is estimated that in the northern United States, almost half of the people who live up to 65 years will develop skin cancer once. This represents growing public concern [3]. In recent years, utilization of herbal medicines along with its active constituents to treat cancer tremendously increased due to lesser side effects [4]. Phytoconstituents which are present in herbal drugs were prominently utilized in cancer treatment due to its multimolecular target action. Herbal drugs contain various types of phytoconstituents having versatile pharmacological actions like alkaloids, glycosides, and tannins. Along with the active ingredients, plants contain vitamins, minerals, proteins, etc. [5]. Nothapodytes 
nimmoniana (Icacinaeae) is mainly tropical and subtropical species which mainly occur in the Western Ghats of Maharashtra, India. Camptothecin (CPT) is a prime phytoconstituent of Nothapodytes nimmoniana which is reported for various pharmacological activities such as antiviral [6], HIV [7], antibacterial, antifungal [8], colorectal cancer, malignancies, ovarian cancer, recurrent small cell lung cancer [9-11], and breast cancer [12]. Camptothecin demonstrates a broad-spectrum anticancer activity. Their molecular target has been firmly established to be the human DNA topoisomerase-I. CPT inhibits topoisomerase-I by blocking the rejoining step of the cleavage reaction of topoisomerase-I, resulting in accumulation of a covalent reaction intermediate, the cleavable complex. The primary mechanism of cell killing by CPT is the S-phase-specific killing through potentially lethal collisions between advancing replication forks and topoisomerase-I cleavable complexes. Collisions with the transcription machinery have also been shown to trigger the formation of long-lived covalent topoisomerase-I DNA complexes, which contribute to CPT cytotoxicity which is significantly responsible for skin cancer activity $[13,14]$. However, no studies have undertaken in the quest of anticancer activity of camptothecin on skin cancer. Side effects that occurred during conventional treatment of melanoma patients treated with chemo and immunotherapy who prominently suffer from anorexia, nausea, fatigue, vomiting, renal toxicity, abdominal pain, dermatitis, hepatitis, and infection among others are avoided by topical herbal gel formulations $[15,16]$. As skin cancer can be better treated by the use of topical gel formulations as these are painless and can be applied at the targeted site, many skin cancers were treated by gel formulation, and there are herbal gel formulations with other aids that have shown better penetration [17]. Hence, the present investigation is aimed to utilize camptothecin isolated from Nothapodytes nimmoniana in treatment of skin cancer by developing a camptothecin herbal gel formulation.

\section{Materials}

Carbopol-934, sodium CMC-HiMedia Labs Pvt. Ltd., Mumbai, Glycerine-Loba Chemie Ptv. Ltd., Mumbai, propylene glycol, propylparaben, methylparaben-Nice Chemicals Pvt. Ltd., Mumbai, Tri-ethanolamine-Ozone Int. Chemicals, Mumbai. Double-distilled water procured from Unique Chemical, Kolhapur. All chemicals and reagents used in present research work were of analytical grade.

\section{Methods}

\section{Preparation of Nothapodytes nimmoniana extract}

Camptothecin was extracted by using microwave irradiation technique from $N$. nimmoniana with the help of surfactant solution (Emulgen). Five grams dried N. nimmoniana plant material was kept in $200 \mathrm{ml}$ of $0.2 \% \mathrm{w} / \mathrm{v}$ surfactant solution of $\mathrm{pH} 8$ in $250 \mathrm{ml}$ Erlenmeyer flask. Suspension of $N$. nimmoniana-containing surfactant was kept in microwave for irradiation for $1 \mathrm{~min}$ at $350 \mathrm{~W}$. Microwave irradiation was stopped after $1 \mathrm{~min}$ and cooled for $2 \mathrm{~min}$. Same procedure was repeated for $3 \mathrm{~min}$. The filtrate of extraction was acidified with $2 \% \mathrm{w} / \mathrm{w}$ sulfuric acid solution until $\mathrm{pH}$ comes to 3-4. Mayer's reagent was added to precipitate alkaloids. The precipitated alkaloids were dissolved in $5 \%$ alkaline solution of $\mathrm{Na}_{2} \mathrm{CO}_{3}$. The organic layer was neutralized by washing with distilled water until it has neutral $\mathrm{pH}$ and was dried and concentrated to get (camptothecin) alkaloids $[18,19]$.

\section{Identification of camptothecin}

Fourier transform infrared spectroscopy (FTIR)

FTIR spectroscopy is utilized to analyze characteristic moieties present in developed formulation. The chemical composition of the camptothecin gel and excipients were studied. Functional moieties present in camptothecin gel were determined and confirmed by FTIR (PerkinElmer FTIR Series model-1615 spectrophotometer), and the spectra was scanned in the range of 4000 to $400 \mathrm{~cm}^{-1}$ range at a resolution of $4 \mathrm{~cm}^{-1}$ [20].

\section{Differential scanning calorimetry (DSC)}

DSC (Mettler Toledo, Stare SW 12.10) equipped with intracooler and refrigerated cooling system was used to obtain the thermogram at a heating rate of $10{ }^{\circ} \mathrm{C}$ per minute over a temperature range of $0-300{ }^{\circ} \mathrm{C}$. Inert condition was maintained by purging nitrogen at $10 \mathrm{ml} / \mathrm{min}$ rate. In an aluminum crucible, the sample was sealed hermetically [21].

\section{Mass spectroscopy}

An esquire LC ion trap system was used for mass spectrometric detection for positive and negative ion mode mass and MS spectra. The capillary voltage was set to $3800 \mathrm{~V}$ and at the end $500 \mathrm{~V}$ plate in + Ve ion mode. The sample was infused directly via a syringe pump, and nebulizer gases were reduced to $5 \mathrm{l} / \mathrm{min}$ and $5 \mathrm{psi}$, respectively. For precision mass detection, a micro TOF-Q equipped with the Apollo ESI ion source was utilized. Capillary voltage was maintained at $4500 \mathrm{~V}$ and end plate voltage to $-500 \mathrm{~V}$ in negative ion mode. The molecular formula was generated by matching high mass accuracy and isotopic pattern [22].

\section{Compatibility study}

The development of formulation drug and polymer are in close contact with each other, and the stability of the developed formulations depends on these interactions. For the determination of compatibility of $\mathrm{CPT}$ and 
excipients, modern analytical techniques such as FTIR and DSC were used to confirm compatibility.

\section{Formulation of camptothecin gel}

With continuous vigorous stirring, Carbopol-934 as a gelling agent and sodium carboxyl methyl cellulose as a thickening agent were dissolved in $50 \mathrm{ml}$ doubledistilled water. Preservative solution was prepared by adding required quantities of preservatives in $5 \mathrm{ml}$ double distilled water on heating water bath. Preservative solution was cooled, and glycerin was added in it. Then, it was mixed with the first resultant solution. Predetermined quantity of camptothecin was added to this solution and mixed homogeneously. Finally, this whole mixture was mixed properly and the $\mathrm{pH}$ was adjusted to skin $\mathrm{pH}(6.8-7)$; triethanolamine was added drop by drop with continuous stirring to obtain a gel of predetermined viscosity and consistency [23] (Table 1).

\section{Evaluation parameters Percentage yield}

The $\%$ practical yield was calculated from the weight of camptothecin gel recovered from each batch in comparison to total starting weight of raw materials [24]. The \% yield was calculated using the following formula.

$$
\text { \%yield }=\frac{\text { Practical mass }}{\text { Theoretical mass }} \times 100
$$

\section{Measurement of $\mathrm{pH}$}

About $20 \mathrm{mg}$ of the camptothecin gel was taken within $24 \mathrm{~h}$ of manufacture in a beaker, and the $\mathrm{pH}$ was measured with the help of a digital pH meter (Hitech Lab India) [25].

\section{Spreadability}

The apparatus consists of a wooden block having a pulley at one end. The drag characteristic of the gel was

Table 1 Formulation table of camptothecin herbal gel

\begin{tabular}{llllll}
\hline Ingredients & \multicolumn{3}{l}{ Quantity } \\
\cline { 2 - 6 } & F1 & F2 & F3 & F4 & F5 \\
\hline Camptothecin (mg) & 100 & 100 & 100 & 100 & 100 \\
Carbopol-940 (g) & 1 & 2 & 1 & 1 & 2 \\
Sodium CMC (g) & 1 & 1 & 2 & 3 & 1 \\
Glycerin (ml) (g) & 2 & 2 & 2 & 2 & 2 \\
Methylparaben (0.5\%) (ml) & 0.2 & 0.2 & 0.2 & 0.2 & 0.2 \\
Propylparaben (0.2\%) $(\mathrm{ml})$ & 5 & 5 & 5 & 5 & 5 \\
Triethanolamine $(\mathrm{ml})$ & q. s. & q. s. & q. s. & q. s. & q. s. \\
Purified water $(\mathrm{ml})$ & 100 & 100 & 100 & 100 & 100 \\
\hline
\end{tabular}

used to measure the spreadability. About $2 \mathrm{~g}$ of the gel sample was placed on a ground slide, and the gel was sandwiched between ground slides which were fixed and having a hook. Weight of $1 \mathrm{~kg}$ was placed on top of slides for 5 minutes due to which formation of uniform gel film between slides. The top plate is subjected to pull $80 \mathrm{~g}$ by using a string attached to the hook; meanwhile, the time required by the top slide to cover the distance of $7.5 \mathrm{~cm}$ was recorded in seconds [26]. Spreadability was calculated by using the following formula:

$$
S=M \times L / T
$$

where $S$ is the spreadability, $M$ is the weight in pan, $L$ is the length moved by the glass slide, and $T$ is the time taken to separate the slide completely from each other.

\section{Extrudability}

Camptothecin gel was incorporated in aluminum collapsible tube which was sealed at one end. The tubes' weights were recorded. The tubes were clamped by placing between 2 glasses. The cap was removed by placing 500 g camptothecin gel over the slides. An extruded amount of gel was weighted after collection, and \% of extrusion was calculated [27].

\section{Drug content}

Accurately weighted $1 \mathrm{~g}$ camptothecin gel was placed in $100 \mathrm{ml}$ phosphate buffer $\mathrm{pH} 5$ as solvent. The resultant solution was continuously shaken until complete dissolution of gel formulation in solvent. The resultant solution was filtered by Whatman filter paper, and drug content was measured with the help of UV visible spectrophotometer (Shimadzu UV-1900) at $225 \mathrm{~nm}$ with the help of calibration curve [28].

Drug content $=$ Actual yield $/$ Theoretical yield $\times 100$

\section{Viscosity}

Brookfield DV-E viscometer (Middleborough, MA, USA) having spindle \#64 was used to measure viscosity of gel formulation at 10 to $100 \mathrm{rpm}$. Viscosity of gel formulations was automatically recorded and displayed on digital screen. Once measurement was over, the spindle was lowered. The digital readings were multiplied by the factor mentioned in the catalog [29].

\section{Diffusion studies}

Diffusion study was carried out with the help of Franz diffusion cell (Logan Instruments) having a capacity of $16 \mathrm{ml}$ equipped with cellophane membrane. Accurately weighted $01 \mathrm{~g}$ camptothecin gel was placed over cellophane membrane in donor compartment and receptor compartment filled with $\mathrm{pH} 6.8$ phosphate buffer. With 
constant stirring, the resultant assembly was placed on a magnetic stirrer at $50 \mathrm{rpm}$. And temperature was kept constant at $37{ }^{\circ} \mathrm{C} \pm 2{ }^{\circ} \mathrm{C}$ by continuous flow of water through jacket. Each time, $1 \mathrm{ml}$ sample was withdrawn at every $1 \mathrm{~h}$ up to $12 \mathrm{~h}$ and same time equals the amount of phosphate buffer was placed in the receptor compartment. Withdrawn samples were analyzed for drug content at $225 \mathrm{~nm}$ against blank by UV-visible spectrophotomer (Shimadzu UV-1900) [27].

\section{Anticancer activity \\ Cell culture}

Cell line was procured from the NCCS (National Centre for Cell Sciences), Pune. The cell line were cultured in DMEM medium which was supplemented with $10 \%$ heat-inactivated fetal calf serum (FBS) and 1\% antibiotic-antimycotic $100 \times$ solution and incubated in $\mathrm{CO}_{2}$ incubator (Eppendorf, New Brunswick, Galaxy 170R, Germany) maintained at $37{ }^{\circ} \mathrm{C}, 5 \% \mathrm{CO}_{2}$ with $95 \%$ humidity until the completion of experiments.

\section{Cytotoxicity}

The cells were seeded at a density of approximately $5 \times 10^{3}$ cells/well in a 96-well flat-bottom micro plate and maintained at $37{ }^{\circ} \mathrm{C}$ in $95 \%$ humidity and $5 \%$ $\mathrm{CO}_{2}$ for overnight. Different concentration $(60,50$, $40,30,20,10 \mu \mathrm{g} / \mathrm{ml}$ ) of samples was treated. For another $48 \mathrm{~h}$, the cells were incubated. The wells were washed with phosphate buffer solution twice and 20 $\mu \mathrm{l}$ of the MTT (3-(4,5-dimethylthiazol-2-yl)-2,5diphenyl tetrazolium bromide) staining solution (5 $\mathrm{mg} / \mathrm{ml}$ in phosphate buffer solution) was added to each well, and the plate was incubated at $37{ }^{\circ} \mathrm{C}$. After $4 \mathrm{~h}, 100 \mu \mathrm{l}$ of dimethyl sulfoxide (DMSO) was added to each well to dissolve the formazan crystals, and absorbance was recorded with $570 \mathrm{~nm}$ using a microplate reader [30].

Formula: Surviving cells $(\%)=$ Mean OD of test compound/Mean OD of negative control $\times 100$

Using graph Pad Prism Version 5.1, we calculate the $\mathrm{IC}_{50}$ of compounds

Surviving cells (\%) - cell viability

Mean OD of test compound-mean optical density of test compound

Mean OD of Negative control-mean optical density of Negative control

$$
\text { OD—optical density }
$$

\section{DAPI (4',6-diamidino-2-phenylindole)}

The cells were seeded at a density of approximately 1 $\times 10^{4}$ cells/well in a 24-well flat-bottom microplate containing cover slips and maintained at $37{ }^{\circ} \mathrm{C}$ in $\mathrm{CO}_{2}$ incubator for overnight. Less than the $50 \mu \mathrm{g} / \mathrm{ml}$ of compounds was treated at $48 \mathrm{~h}$. After the incubation, the cells were washed with PBS and fixed with $4 \%$ paraformaldehyde for $30 \mathrm{~min}$. Twenty microliters of DAPI $(0.1 \mu \mathrm{g} / \mathrm{ml})$ was incubated for $5 \mathrm{~min}$ at room temperature in the dark and examined under fluorescent microscope, randomly selecting the fields in the microscope and counted the number of cells undergone apoptosis and then calculated the percentage of apoptotic cells [31].

\section{Results and discussion Identification of camptothecin FTIR spectroscopy}

The use of FTIR technique allowed pointing out the implication of the different functional groups of guest and host molecules by analyzing the significant changes in the size and position of the absorbance bands. The principal absorption peak of standard camptothecin which showed $\mathrm{OH}$ stretching at $3437.29 \mathrm{~cm}^{-1}$, ester stretching at $1741.78 \mathrm{~cm}^{-1}, \mathrm{C}=\mathrm{O}$ stretching at $1642.28 \mathrm{~cm}^{-1}, \mathrm{C}=\mathrm{C}$ at $1621.28 \mathrm{~cm}^{-1}, \mathrm{C}=\mathrm{N}$ at $1438.94 \mathrm{~cm}^{-1}, \mathrm{C}-\mathrm{O}$ at 1033.88 $\mathrm{cm}^{-1}$, and peak at $775.41 \mathrm{~cm}^{-1}$ appears to be a contribution of four adjacent hydrogen bonds on the heteroaromatic nucleus. The values are near or equal to the values mentioned in the standard structure of camptothecin [32] (Fig. 1).

\section{Differential scanning calorimetry (DSC)}

DSC gives information about the transition temperature by comparing resulted thermal transition which includes melting decomposition and outgassing for change in the heat capacity. DSC spectra shows sharp exothermic and endothermic melting temperatures at $278.56{ }^{\circ} \mathrm{C}$ and $346.91{ }^{\circ} \mathrm{C}$, respectively, which confirms the purity of isolated moiety by its melting point [33] (Fig. 2).

\section{Mass spectroscopy}

Mass spectroscopy gives information about the molecular weight of the specific compound which is the most important confirmatory test for the identification of isolated moieties which exactly matches with the standard molecular weight of standard camptothecin. The mass spectra of camptothecin give precursor $\mathrm{m} / \mathrm{z}$ peak at $349.2[\mathrm{M}+\mathrm{H}]+$ in plain, and the mass spectra match with the peak for standard camptothecin [34-36]. Results were shown in Fig. 3.

\section{Compatibility studies}

Compatibility between camptothecin and other excipients was confirmed by FTIR study of camptothecin herbal gel formulation and was recorded and compared. The FTIR spectrum of camptothecin herbal gel formulation shows characteristic peaks of functional group at $\mathrm{C}=\mathrm{C}$ Str. (Ar. Ring)-1652.46, C-H Str. (Alkyl)-2938.89, C-H det-1364.88, C=O Str-1704.47, 

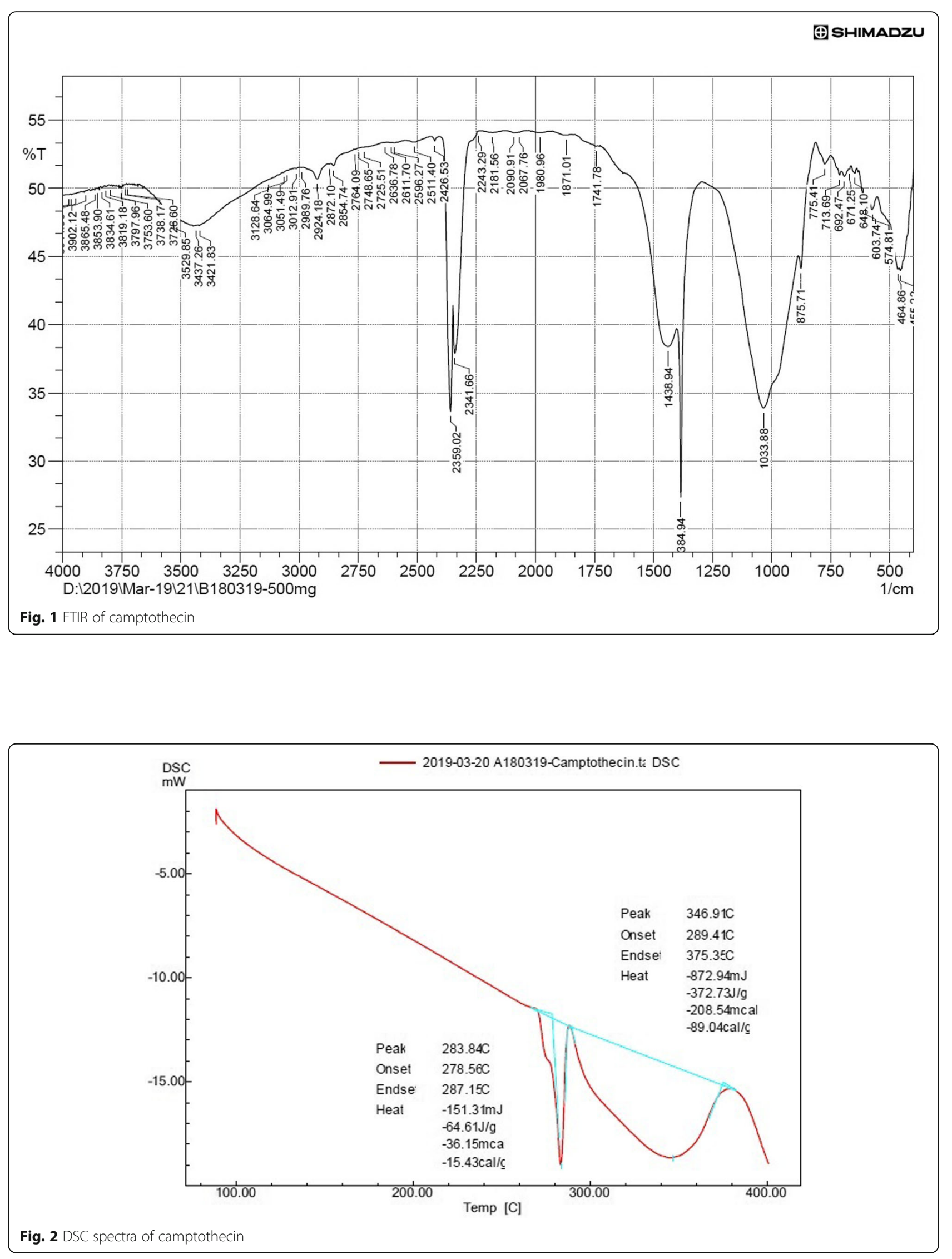


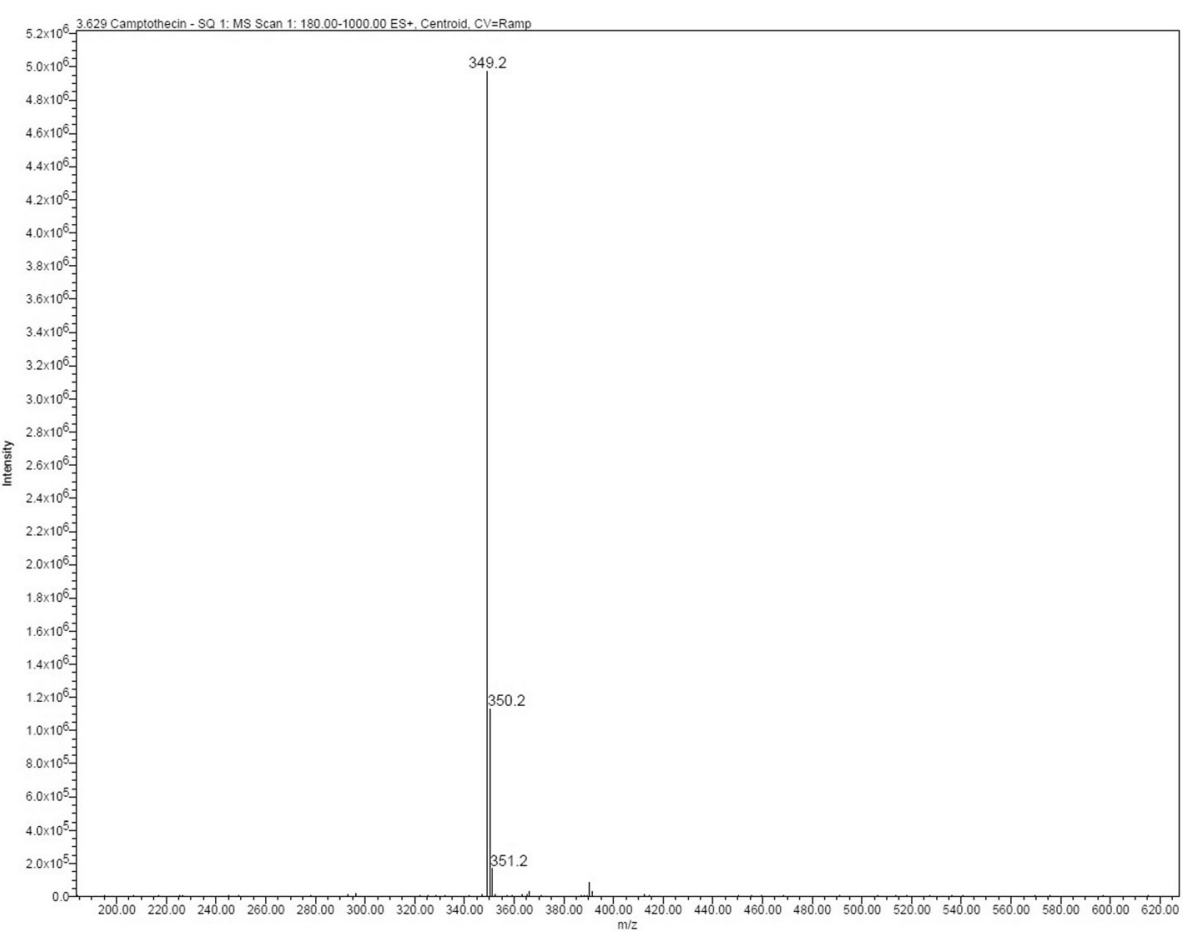

Fig. 3 Mass spectra of camptothecin

and C-N Str. (Aryl N)-1450.23. FTIR results clearly indicate compatibility among camptothecin, excipients, and processing condition and the integrity of camptothecin was unaffected after conversion into herbal gel. Results were shown in Fig. 4.

\section{Differential scanning calorimetry (DSC)}

The results of DSC analysis showed that the exothermic melting temperature for camptothecin was at $278.56{ }^{\circ} \mathrm{C}$. The integrity of the camptothecin remained unaffected after formulation into herbal gel; this is confirmed by

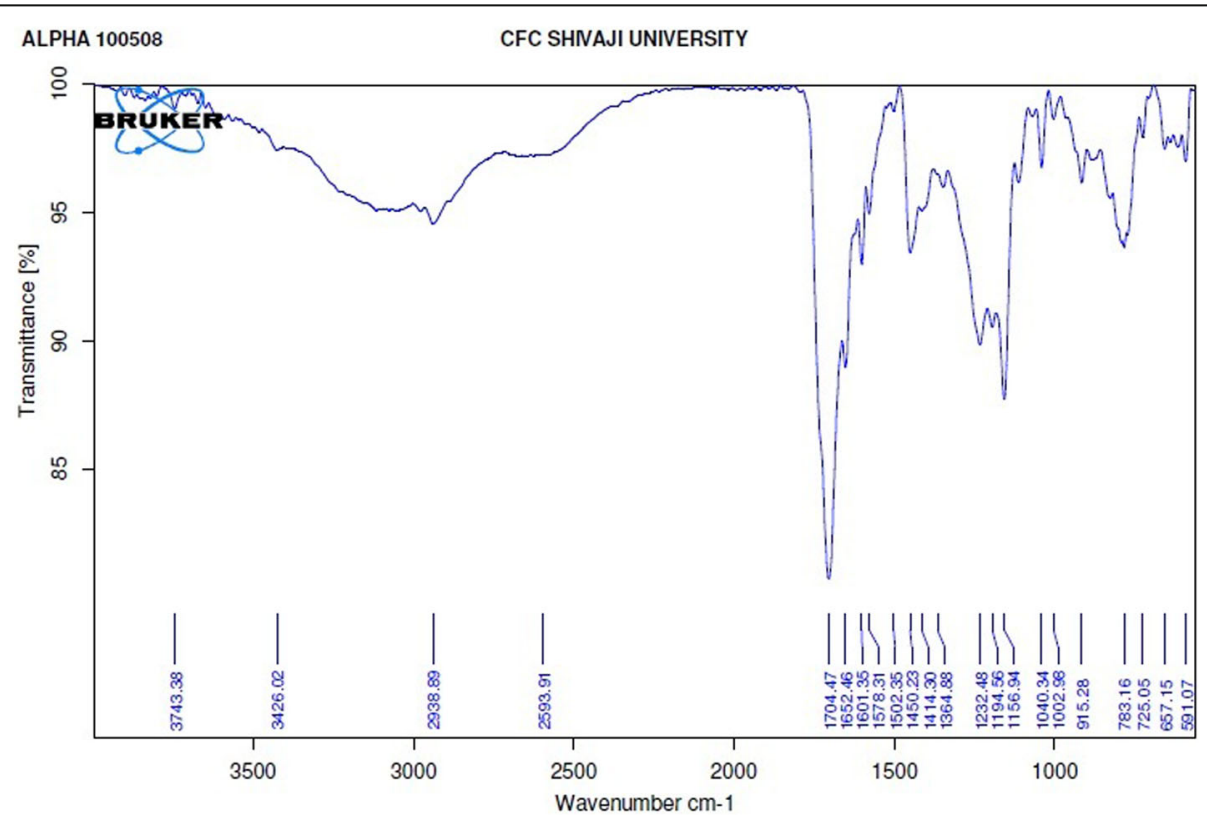

Fig. 4 FTIR of camptothecin herbal gel formulation 
the DSC of formulation where the composite melting peaks of camptothecin was found to be at $245.24{ }^{\circ} \mathrm{C}$, indicating compatibility between camptothecin, polymer, and processing conditions. The results of DSC thermograms are shown in Fig. 5.

\section{Evaluation of herbal gel of camptothecin}

Camptothecin gel formulations were prepared by using various concentrations of Carbopol-934 as gelling agent and sodium CMC polymer, keeping the concentration of all excipients including that of camptothecin constant, so as to check the effect of concentration of the gelling agent and the polymer. The formed herbal gels were inspected physically and were found to be brownish in color and smooth.

\section{Percentage yield}

Percentage yields of all the five formulations were very high and were affected by the concentration of the polymer; the increase in polymer concentration leads to an increase in percentage yield. The percentage yield of all herbal gels was found to be in the range of 93.78 to 97.41\%. Results were shown in Table 2.

\section{$\mathrm{pH}$ measurement}

Camptothecin gel formulations' $\mathrm{pH}$ was measured by a digital $\mathrm{pH}$ meter. The $\mathrm{pH}$ of all herbal gel formulations was in between 6.7 and 6.9 range. The $\mathrm{pH}$ of all formulations is shown in Table 2.

\section{Spreadability study}

All the prepared camptothecin gel formulations were evaluated for spreadability. Spreadability of all herbal gels was in between $15.81 \mathrm{~g} \cdot \mathrm{cm} / \mathrm{s}$ to $23.27 \mathrm{~g} \cdot \mathrm{cm} / \mathrm{s}$ range. As the concentration of sodium CMC increases, the spreadability of formulation increases. The spreadability of all formulations was shown in Table 2.

\section{Extrudability study}

All the prepared herbal gels were evaluated for extrudability. The extrudability of all herbal gel formulations was in between 85.51 and $90.45 \%$ w/w range indicating good extrudability. The extrudability of all formulations is shown in Table 2.

\section{Drug content}

The drug content of herbal gel formulations was found to be in the range of $89.12-96.64 \%$. Formulation F3 showed high drug content (96.64\%). This indicates that the drug is uniformly distributed throughout the system. The analyzed drug content displayed in Table 2.

\section{Viscosity analysis}

The viscosity of herbal gel formulations was primarily depending on the polymeric content of the formulation. The viscosity of the formulation is dependent on the polymer; the viscosity increases as the ratio of the polymer increases. Results are shown in Fig. 6.

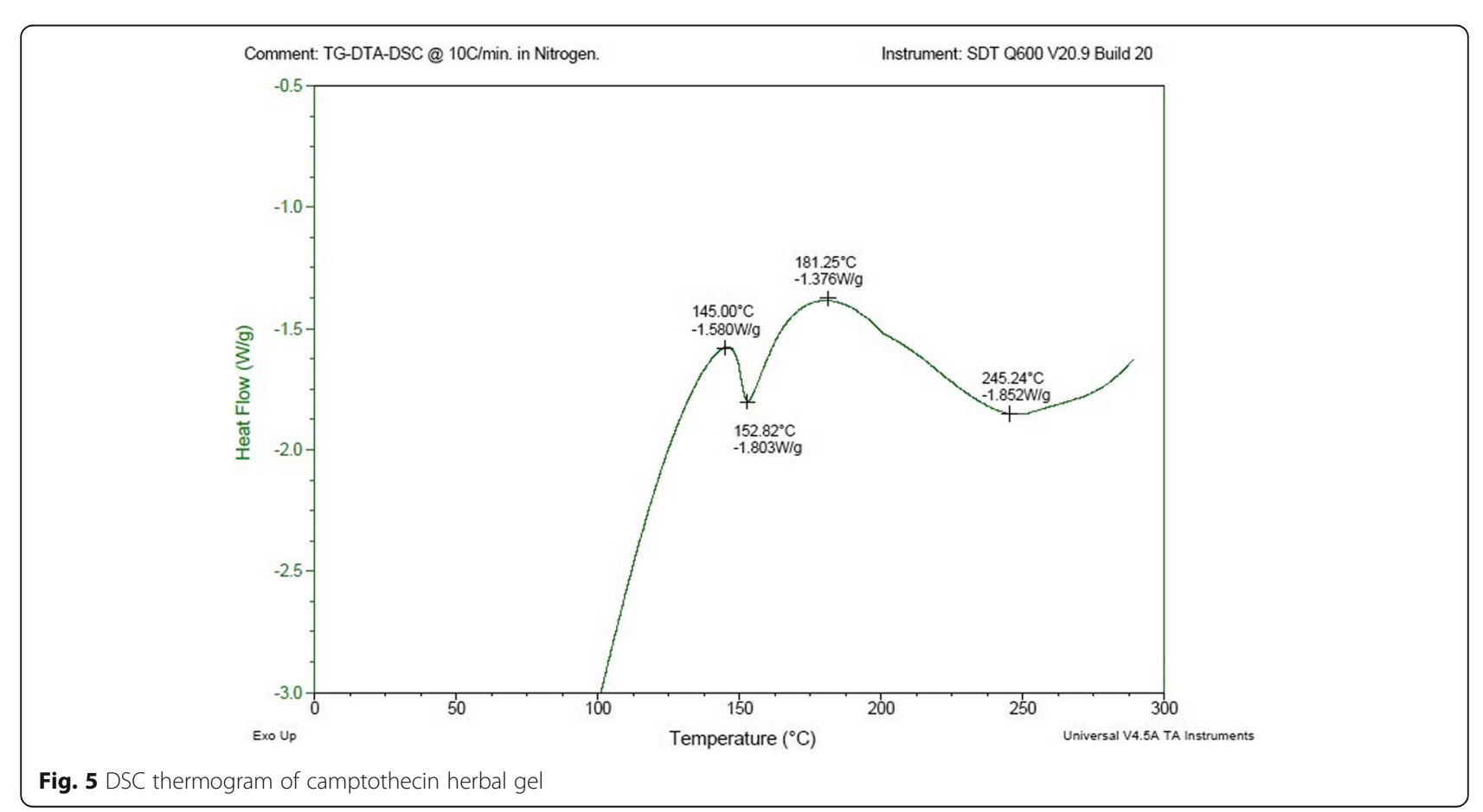


Table 2 Evaluation parameters of camptothecin gel formulation

\begin{tabular}{|c|c|c|c|c|c|}
\hline \multirow[b]{2}{*}{ Parameter } & \multicolumn{5}{|c|}{ Formulation code } \\
\hline & F1 & $\mathrm{F} 2$ & F3 & F4 & F5 \\
\hline $\mathrm{pH}^{*}$ & $6.71 \pm 0.03$ & $6.83 \pm 0.05$ & $6.68 \pm 0.02$ & $6.81 \pm 0.04$ & $6.90 \pm 0.03$ \\
\hline Spreadability* $(\mathrm{g} \cdot \mathrm{cm} / \mathrm{s})$ & $15.81 \pm 0.42$ & $17.93 \pm 0.35$ & $20.04 \pm 0.53$ & $22.16 \pm 0.50$ & $23.27 \pm 0.31$ \\
\hline Extrudability* (\% w/w) & $86.32 \pm 0.10$ & $85.51 \pm 0.12$ & $90.45 \pm 0.11$ & $89.64 \pm 0.11$ & $88.57 \pm 0.13$ \\
\hline Drug content (\% w/w) & $89.12 \pm 1.3$ & $90.61 \pm 1.1$ & $96.64 \pm 1.2$ & $94.31 \pm 0.8$ & $92.76 \pm 1.0$ \\
\hline$\%$ Yield & 93.78 & 95.85 & 96.33 & 96.72 & 97.41 \\
\hline
\end{tabular}

*Each value represents mean \pm S.D. of three observations

\section{Diffusion study}

Diffusion study of camptothecin herbal gel formulation was performed by Franz diffusion cell using phosphate buffer as solvent for $8 \mathrm{~h}$. All formulations F1 to F5 containing Carbopol-934 and sodium CMC in different ratio has shown the drug release of $88.36 \%, 93.42 \%, 97.84 \%$, $98.40 \%$, and $89.40 \%$, respectively, after $8 \mathrm{~h}$ as shown in Fig. 7. Results' regression coefficient values from different kinetic models are shown in Table 3.

\section{Anticancer activity}

The cytotoxicity of viability of the camptothecin gel was evaluated using MTT assay. The $\mathrm{IC}_{50}$ value of camptothecin gel was found to be $48.03 \mu \mathrm{g} / \mathrm{ml}$. As the concentration of gel increases, the cell viability decreases, which shows a dose-dependent cytotoxicity. When compared to untreated cells, camptothecin geltreated cells showed significant cell death $(P<0.01)$ as shown in Fig. 8.

A

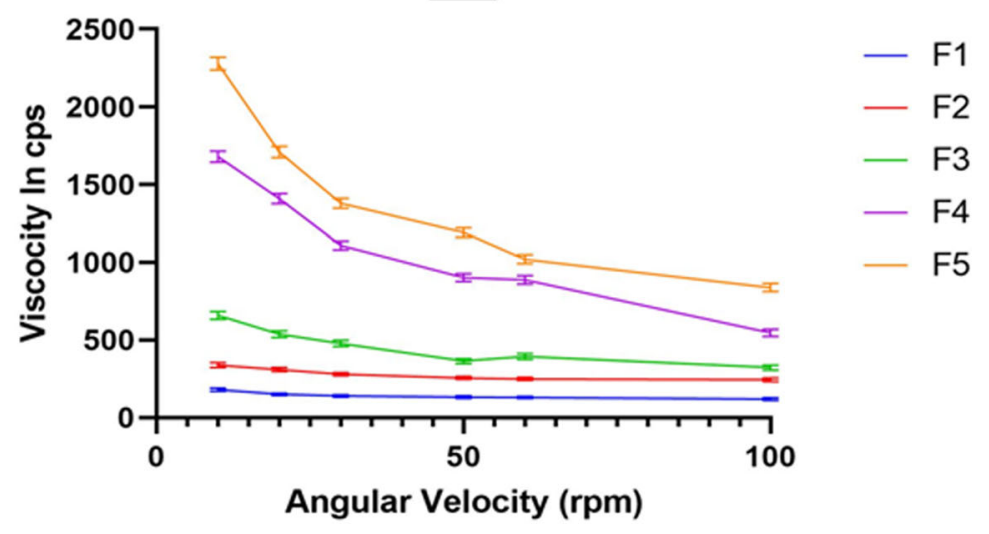

B

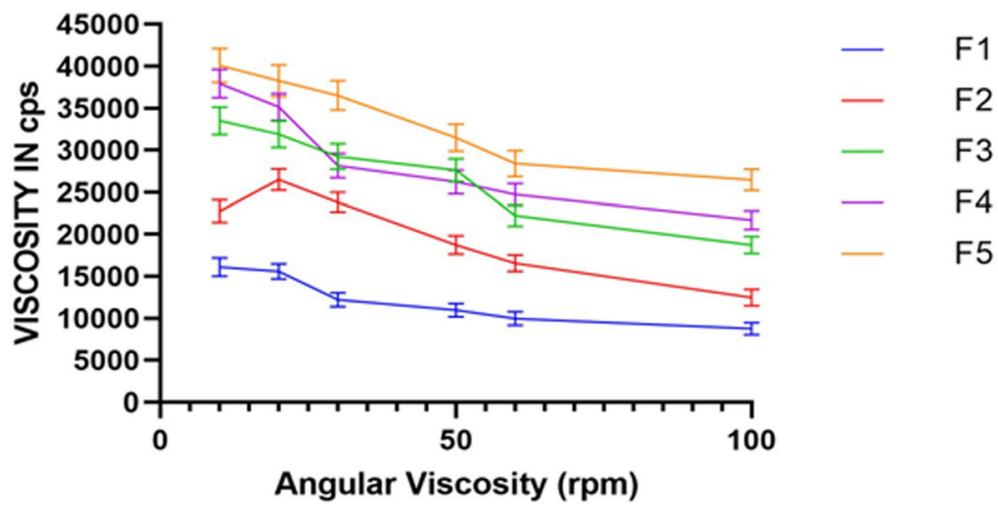

Fig. 6 Viscosity of camptothecin herbal gel a before gelation and b after gelation 


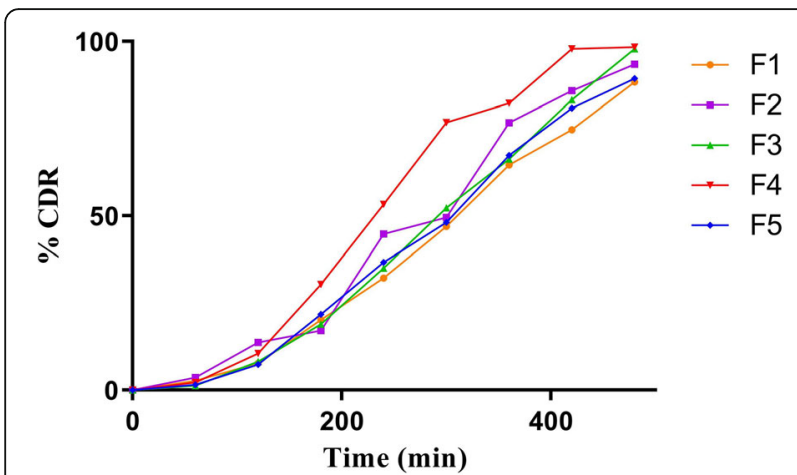

Fig. 7 Zero-order release kinetics of CPT herbal formulation

DAPI is a dye used to stain nucleus to characterize the stages of apoptosis. The apoptotic nuclear morphology changes in A-439 cells following the treatment with camptothecin gel for $48 \mathrm{~h}$ were observed. The fluorescence microscopic photographs of untreated cells showed round intact nucleus, whereas camptothecin geltreated cells showed condensed nucleus and fragmentation of DNA occurs as shown in the Fig. 9. The apoptosis (\%) for control and camptothecin gel is $3.25 \pm 1.11$ and $54.67 \pm 4.58$, respectively.

\section{Discussion}

Chemical fingerprinting of isolated camptothecin was performed by FTIR, DSC, and mass spectroscopy. FTIR spectra values are near or equal to the values mentioned in the standard structure of camptothecin. Compatibility study of camptothecin excipients and processing conditions was performed comparing FTIR and DSC spectra of camptothecin; its formulation confirms that the peaks of the characteristic functional group of camptothecin are retained in the formulation. DSC is a tool which provides qualitative physiochemical status of camptothecin and by comparing DSC spectra of camptothecin and its formulation for possible interactions, it was confirmed that composite melting peaks of camptothecin was retained in the formulation which is an indication of no effect of processing parameters of potency of camptothecin. Optimized camptothecin gel was evaluated for its

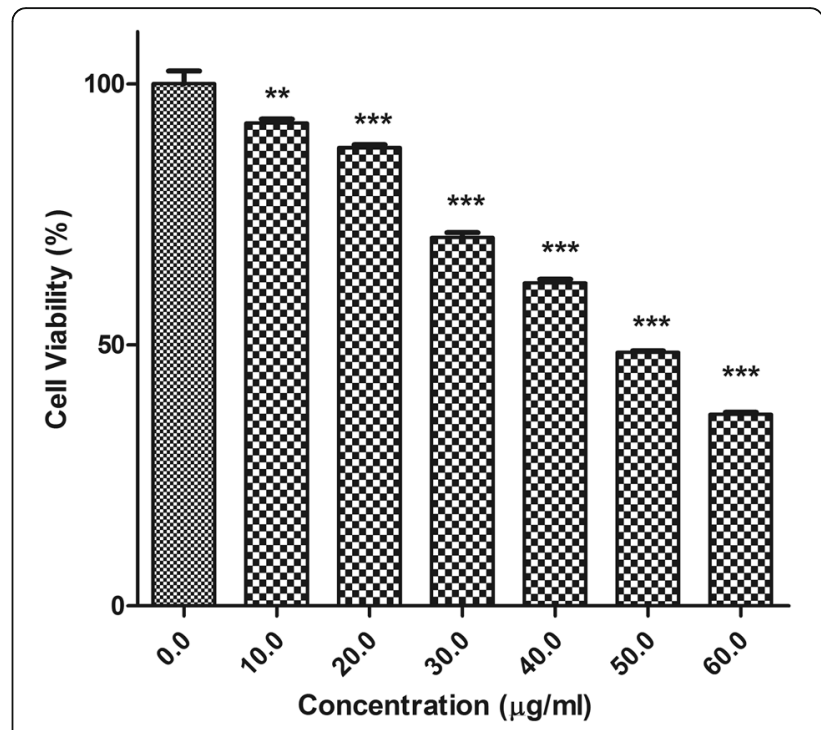

Fig. 8 Cell viability vs concentration on skin cancer cell lines A431

$\mathrm{pH}$, spreadability, extrudability, and drug content. All parameters were found to be satisfactory. Viscosity study clearly indicates that as the polymer concentration increases, the viscosity of the gel also increases after and before gelation. Kinetics modeling and regression values further demonstrate that the release kinetic study of all formulations followed a zero order and diffusioncontrolled order. To evaluate the cytotoxicity of the developed camptothecin gel for their possible use as an anticancer agent has its own vital importance. The in vitro cytotoxicity of CPT gel was investigated against A-439 cell line by MTT assay. Figure 8 showed the percentage viability of CPT gel for $48 \mathrm{~h}$. The viability of A-439 cells treated with concentrations $(1-60 \mu \mathrm{g} / \mathrm{ml})$ exhibited concentration-dependent cytotoxicity. The untreated cells (Fig. 9a) displayed normal intact nuclei with weak homogenous blue staining, whereas in the groups treated with CPT gel (Fig. 9b) showed small nuclei with bright chromatin condensation, nuclear fragmentation, and apoptotic body (small spherical fragments) formation. The results indicate that camptothecin induce apoptosis in A-431 cell fragmentation of nuclei and uneven edges

Table 3 Kinetic modeling of drug release from herbal gel formulations

\begin{tabular}{|c|c|c|c|c|c|c|c|c|}
\hline \multirow{2}{*}{$\begin{array}{l}\text { Formulation } \\
\text { code }\end{array}$} & \multicolumn{2}{|c|}{ Zero order } & \multicolumn{2}{|c|}{ First order } & \multicolumn{2}{|c|}{ Higuchi's equation } & \multicolumn{2}{|c|}{ Peppa's equation } \\
\hline & $\overline{R^{2}}$ & Slope & $\overline{R^{2}}$ & Slope & $\overline{R^{2}}$ & Slope & $\overline{R^{2}}$ & Slope \\
\hline $\mathrm{F} 1$ & 0.9738 & 0.1972 & 0.8688 & 0.0018 & 0.8109 & 4.251 & 0.8033 & 1.479 \\
\hline$F 2$ & 0.9639 & 0.2164 & 0.8677 & 0.0023 & 0.8170 & 4.705 & 0.8483 & 1.504 \\
\hline F3 & 0.9700 & 0.2186 & 0.7228 & 0.0028 & 0.7989 & 4.686 & 0.7207 & 1.541 \\
\hline $\mathrm{F} 4$ & 0.9617 & 0.2419 & 0.8489 & 0.0039 & 0.8494 & 5.368 & 0.7891 & 1.596 \\
\hline F5 & 0.9753 & 0.2060 & 0.8811 & 0.0019 & 0.8173 & 4.455 & 0.7781 & 1.508 \\
\hline
\end{tabular}



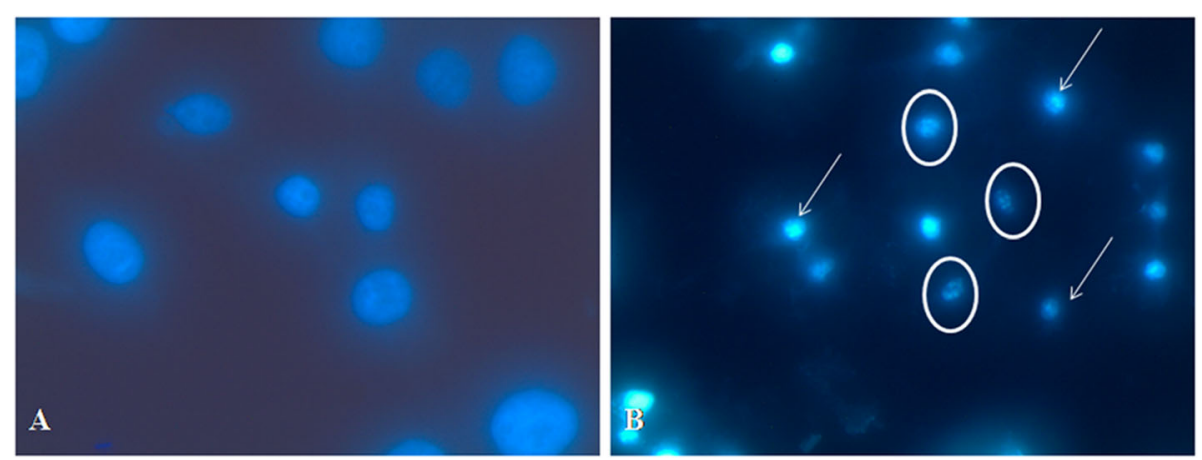

Fig. 9 a Negative control activity on skin cancer cell lines A431. b Anticancer activity of camptothecin gel on skin cancer cell lines A431

nearby the nuclei in cells treated with camptothecin gel which are an indication of cell undergoing apoptosis.

\section{Conclusion}

From the results, it can be concluded that camptothecin isolated form Nothapodytes nimmoniana can be delivered in the form of herbal gel formulation by transdermal route with the help of Carbopol-934 and sodium CMC as the polymer. The controlled release can be achieved for a longer period of time by using these herbal gel formulations; hence, the developed herbal gel formulation can be effectively useful to deliver camptothecin in the treatment of skin cancer which is proved by anticancer activity on the epidermoid carcinoma cell line-A431 having an $\mathrm{IC}_{50}$ value of $48.03 \mu \mathrm{g} / \mathrm{ml}$ and $\%$ apoptosis of $54.67 \pm 4.58$.

\section{Abbreviations \\ A-431 cells: Human epidermoid carcinoma cells; CPT: Camptothecin; Sodium CMC: Sodium carboxyl methyl cellulose; FTIR: Fourier transform infrared spectroscopy; pH: Hydrogen ion concentration; UV: Ultraviolet; DSC: Differential scanning calorimetry; F: Formulation code for herbal gel formulations; CDR: Cumulative drug release; SQRT: Square root of time; SD: Standard deviation; OD: Optical density}

\section{Acknowledgments}

The authors are thankful to the Department of Pharmaceutics SGMCP, Mahagaon, and the Trustees of Sant Gajanan Maharaj College of Pharmacy, Mahagaon, for providing the required facilities, guidance, and support to complete the present research work. The authors are also thankful to NCBI, Pune, for providing the skin cancer cell lines A431 and Maratha Mandal Dental College and the research center Belagavi for the anticancer activity.

\section{Plant source}

The whole plant of Nothapodytes nimmoniana family (Icacinaceae) was collected from the Ajara Forest Region and identified and authenticated by Dr. Suresh.G. Killedar, principal of SGMCP Mahagaon, Maharashtra, India, and the voucher specimen No.SGMCP/PH.COG/HERB/01-2019 herbarium was deposited in the pharmacognosy department of SGMCP, Mahagaon, Shivaji University, Kolhapur.

\section{Authors' contributions}

$\mathrm{SG}, \mathrm{AH}, \mathrm{RG}$, and $\mathrm{OM}$ are the researchers who carried out the isolation and all the research activities related to camptothecin; SG has a major contribution in writing the manuscript; SK and DA are the supervisors who guided in the design and characterization of camptothecin gel; VK has a major contribution in monitoring the anticancer studies and in writing the discussion. All authors read and approved the final manuscript.

\section{Funding}

No funding was obtained for this study.

\section{Availability of data and materials}

The datasets used and/or analyzed during the current research work are available from the corresponding author on reasonable request.

\section{Ethics approval and consent to participate}

Not applicable.

\section{Consent for publication}

Not applicable.

\section{Competing interests}

The authors declare that they don't have any competing interests.

\section{Author details}

${ }^{1}$ Sant Gajanan Maharaj College of Pharmacy, Mahagaon, Site: Chinchewadi, Kolhapur, Maharashtra 416502, India. ${ }^{2}$ Bharati Vidyapeeth College of Pharmacy, Near Chitranagari, Morewadi, Kolhapur, Maharashtra 416013, India. ${ }^{3}$ Central Research Laboratory, Maratha Mandal's Nathajirao G. Halgekar Institute of Dental Sciences \& Research Center, Belgavi, Karnataka 590010, India.

Received: 1 May 2020 Accepted: 23 July 2020

Published online: 05 August 2020

\section{References}

1. Nagai H, Kim YH (2017) Cancer prevention from the perspective of global cancer burden patterns. Journal of Thoracic Disease 9(1):448-451

2. Nadaf SJ, Killedar SG (2018) Curcumin nanocochleates use of design of experiments, solid state characterization, in vitro apoptosis and cytotoxicity against breast cancer MCF-7 cells. Journal of Drug Delivery Science and Technology 47(1):337-350

3. Kristjan O, Matevz P, Uros M (2017) Skin cancer and its treatment: novel treatment approaches with emphasis on nanotechnology. J Nanomater $1(1): 1-20$

4. Yeap SK, Abu N, Mohamad NE, Beh BK, Ho WY, Ebrahimi S, Yusof HM, Alitheen NB (2015) Chemopreventive and immunomodulatory effects of Murraya koenigii aqueous extract on 4T1 breast cancer cell-challenged mice. BMC Complement Altern Med 15:306-316

5. Javed I, Banzeer AA, Tariq M, Sobia K, Barkat A, Shah SA, Khalil AT (2017) Plant derived anticancer agents: a green anticancer approach. Asian Pac J Trop Biomed 7(1):1129-1150

6. Kan XW, Justin JH (2017) Antiviral screen identifies EV71 inhibitors and reveals camptothecin-target, DNA topoisomerase 1 as a novel EV71 host factor. Antivir Res 143:122-133

7. Li Y-Y, Chen S-W, Yang L-M (2010) The anti-HIV actions of 7- and 10substituted camptothecins. Molecules. 15:138-148

8. Dong Q, Luo J, Qiu W (2016) Inhibitory effect of camptothecin against rice bacterial brown stripe pathogen Acidovorax avenae subsp. avenae RS-2. Molecules 21:978 
9. Pommier YH (2012) DNA topoisomerases and cancer. Cancer Drug Discovery and Development:1-12

10. Pommier $Y$ (2006) Topoisomerase I inhibitors: camptothecins and beyond. Nat Rev Cancer 6(19):789-802

11. Pommier $Y$ (2013) Drugging topoisomerases: lessons and challenges. ACS Chem Biol 8(1):82-95

12. Tesauro C, Simonsen AK, Andersen MB (2019) Topoisomerase I activity and sensitivity to camptothecin in breast cancer-derived cells: a comparative study. BMC Cancer 19:1158

13. Liu L-F, Desai SD, Li TK, Mao Y, Sun M, Sim SP (2000) Mechanism of action of camptothecin. Ann N Y Acad Sci 922:1-10

14. Li F, Jiang T, Li Q, Ling X (2017) Camptothecin (CPT) and its derivatives are known to target topoisomerase I (Top1) as their mechanism of action: did we miss something in CPT analogue molecular targets for treating human disease such as cancer. Am J Cancer Res 7(12):2350-2394

15. Legha SS, Ring S, Bedikian A (1996) Treatment of metastatic melanoma with combined chemotherapy containing cisplatin, vinblastine and dacarbazine (CVD) and biotherapy using interleukin-2 and interferon. Ann Oncol 7(8): 827-835

16. Rosenberg SA, Yang JC, Schwartzentruber DJ (1999) Prospective randomized trial of the treatment of patients with metastatic melanoma using chemotherapy with cisplatin, dacarbazine, and tamoxifen alone or in combination with interleukin-2 and interferon alfa-2b. J Clin Oncol 17(3): 968-975

17. Margetts L, Sawyer R (2007) Transdermal drug delivery: principles and opioid therapy. The Board of Management and Trustees of the British Journal of Anaesthesia 7(5):171-176

18. Mishra U, Murthy PN, Pasa G, Kumar S (2011) Formulation development and standardization of herbal gel containing methanolic extract of Butea frontosa. International Research Journal of Pharmacy 2(11):126-129

19. Uma G, Balasubramaniam V (2012) GC-MS analysis of Nothapodytes nimmoniana [J. Graham] mabberly leaves. J Chem Pharm Res 4(9):4417-4419

20. Bhaishaikh IM, Galatage ST (2019) Floating microsponges as gastro retentive drug delivery system containing lafutidine to treat gastric ulcer. Acta scientific pharmaceutical sciences 32:3-12

21. Galatage ST, Killedar SG (2019) Development and characterization of micro sponge of amphotercin B for topical drug delivery. RJPBCS 10:1288-1300

22. Negi A, Sharma N, Singh MF (2012) Formulation and evaluation of an herbal anti-inflammatory gel containing Eupatorium leaves extract. Journal of Pharmacognosy and Phytochemistry 1(4):112-117

23. Fulzele DP, Satdive RK (2005) Comparison of techniques for the extraction of the anti-cancer drug camptothecin from Nothapodytes foetida. J Chromatogr 1063(21):9-13

24. Mulla RD, Kondawar MS (2012) Development and validation of uv-visible spectrophotometric method for quantification of camptothecin from Nothapodytes nimmoniana. Inventi Rapid: Pharmaceutical Analysis \& Quality Assurance Publication 331:1-7

25. Sumeet $\mathrm{G}$, Shailesh $\mathrm{G}$ (2012) Formulation and evaluation of herbal gel containing Sesbania grandiflora Poir. leaf extracts. Acta Chimica Pharmaceutica Indica 2(1):54-59

26. Das MK, Maurya D (2008) Evaluation of diltiazem hydrochloride loaded mucoadhesive microspheres prepared by emulsification-internal gelation technique. Acta Pol Pharm Drug Res 65(2):249-259

27. Mohammed HKP, Abraham A, Saraswathi R, Mohanta GP, Naya C (2011) Formulation and evaluation of herbal gel of Basella alba for wound healing activity. International Research Journal of Pharmaceuticals 1(1):15-20

28. Vats A, Sharma P (2012) Formulation and evaluation of topical anti acne formulation of coriander oil. International Journal of Pharmacy and Pharmaceutical Science Research 2(3):61-66

29. Missal G, Dixit G, Gulkari V (2012) Formulation and evaluation of herbal gel. Indian J Nat Prod Resour 3(4):501-505

30. Kumbar VM, Peram MR, Kugaji MS, Shah T, Patil SP, Muddapur UM, Bhat KG (2020) Effect of curcumin on growth, biofilm formation and virulence factor gene expression of Porphyromonas gingivalis. Odontology 1:148-156

31. Peram MR, Jalalpure S, Kumbar V, Patil S, Joshi S, Bhat K, Diwan P (2019) Factorial design based curcumin ethosomal nanocarriers for the skin cancer delivery: in vitro evaluation. Journal of liposome research 29(3):291-311

32. Patil A, Patil S (2014) UV, FTIR, HPLC confirmation of camptothecin an anticancer metabolite from bark extract of Nothapodytes nimmoniana (J. Graham). American Journal of Ethnomedicine 1(3):174-185
33. Thakral NK, Ray AR, Bar-Shalom D (2012) Soluplus-solubilized citrated camptothecin: a potential drug delivery strategy in colon cancer. AAPS PharmSciTech 13(1):59-66

34. Puri SC, Bhat BA (2005) Separation of 9-methoxycamptothecin and camptothecin from Nothapodytes foetida by semipreparative HPLC. J Chromatogr Sci 43(1):348-350

35. Ramesha BT, Amna T, Ravikanth G (2008) Prospecting for camptothecines from Nothapodytes nimmoniana in the Western Ghats, South India: identification of high-yielding sources of camptothecin and new families of camptothecines. J Chromatogr Sci 46(1):362-368

36. Nalluri BN, Devineni PK (2015) Studies on development of controlled release matrix tablets of camptothecin —an anticancer drug. Indian Journal of Pharmaceutical Education and Research 49(4):292-300

\section{Publisher's Note}

Springer Nature remains neutral with regard to jurisdictional claims in published maps and institutional affiliations.

\section{Submit your manuscript to a SpringerOpen ${ }^{\circ}$ journal and benefit from:}

- Convenient online submission

- Rigorous peer review

- Open access: articles freely available online

- High visibility within the field

- Retaining the copyright to your article

Submit your next manuscript at $>$ springeropen.com 